\begin{tabular}{|l|l|l|}
\hline Revista & \multicolumn{2}{|c|}{$\begin{array}{l}\text { Revista Latina de Sociología (RELASO) } \\
\text { Vol. 9, núm.2 (2019), pp. 4-23 } \\
\text { ISSN-e 2253-6469 } \\
\text { Dot: https://doi.org/10.17979/relaso.2019.9.2.6825 } \\
\text { de Sociologia }\end{array}$} \\
\hline
\end{tabular}

\title{
Ressonâncias metodológicas para a investigação qualitativa: $o$ estudo das fratrias
}

\section{Resonancias metodológicas para la investigación \\ cualitativa: el estudio de las fratrias \\ Studying siblings: methodological resonances for qualitative research}

\begin{abstract}
Andreia Barbas
Faculdade de Economia e Centro de Estudos Socais da Universidade de Coimbra andreiabarbas@fe.uc.pt ORCID: https://orcid.org/0000-0001-5458-2761 Sílvia Portugal Faculdade de Economia e Centro de Estudos Socais da Universidade de Coimbra sp@fe.uc.pt ORCID: https://orcid.org/0000-0002-7044-7946
\end{abstract}

Recibido: 07/11/2019 Acedptado: 13/07/2020 


\begin{tabular}{|l|l|l|}
\hline Revista & & $\begin{array}{l}\text { Revista Latina de Sociología (RELASO) } \\
\text { Vol. 9, núm.2 (2019), pp. 4-23 } \\
\text { ISSN-e 2253-6469 } \\
\text { Latina }\end{array}$ \\
de Sociologttps://doi.org/10.17979/relaso.2019.9.2.6825 \\
\hline
\end{tabular}

\section{RESUMO}

O artigo resulta de uma investigação sociológica acerca das relações entre irmã/os. Partindo de um conjunto de reflexões suscitadas pelas características deste objeto, apresentam-se as opções metodológicas tomadas, defendendo o seu potencial heurístico para a compreensão de outros fenómenos.

A investigação em curso encarou as fratrias na sua complexidade e multiplicidade, defendendo que estas devem ser compreendidas através da diversidade e temporalidade das trajetórias individuais e familiares. Deste modo, defende uma abordagem qualitativa que dê conta, simultaneamente das práticas e das representações, do quotidiano e do extraordinário, dos sentidos e significados atribuídos pelos atores.

$\mathrm{O}$ artigo apresenta os percursos seguidos no decorrer da pesquisa, defendendo que a combinação de técnicas de recolha de dados - no caso, entrevistas em profundidade, com carácter de história de vida, e foto-elicitação durante o momento da entrevista - contem virtualidades para a compreensão do fenómeno em análise, que podem ser transferíveis para distintos objetos.

A investigação de base foi realizada em Portugal, entre 2018 e 2019, e teve por base uma amostra composta por irmãs/os e meias/os irmãs/os, integradas/os em 25 fratrias, nas quais todos os elementos foram entrevistados. Tem-se como objetivos discutir: a) a articulação entre a conceptualização do objeto e as opções epistemológicas e metodológicas tomadas; b) a importância metodológica das opções acerca da escolha dos sujeitos a inquirir; c) as vantagens em combinar as duas técnicas de recolha de dados. Apresentar os principais resultados.

Palavras-chave: Investigação qualitativa; metodologia; técnicas qualitativas; relações familiares; fratrias; complexidade. 


\begin{tabular}{|l|l|l|}
\hline Revista & Revista Latina de Sociología (RELASO) \\
Latina & Vol. 9, núm.2 (2019), pp. 4-23 \\
ISSN-e 2253-6469 \\
DoI: https://doi.org/10.17979/relaso.2019.9.2.6825
\end{tabular}

\section{RESUMEN}

El artículo es el resultado de una investigación sociológica sobre las relaciones entre hermanos. Partiendo de un conjunto de reflexiones planteadas por las características de este objeto, presentamos las opciones metodológicas, discutiendo sobre su potencial heurístico para comprender otros fenómenos.

La investigación analiza las relaciones entre hermanos en su complejidad y multiplicidad, argumentando que deben entenderse a través de la diversidad y la temporalidad de las trayectorias individuales y familiares. Por lo tanto, defiende un enfoque cualitativo que explica simultáneamente las prácticas y las representaciones, lo cotidiano y lo extraordinario, los sentidos y los significados atribuidos por los actores.

El artículo presenta los caminos seguidos durante la investigación, argumentando que la combinación de técnicas de recopilación de datos, en este caso, entrevistas en profundidad, bajo la modalidad de historia de vida, y la photo-elicitación durante la entrevista, contiene virtualidades para comprender el fenómeno bajo análisis, que puede ser transferible a diferentes objetos.

La investigación se llevó a cabo en Portugal, entre 2018 y 2019, con una muestra de hermanos y medio hermanos, integrada en 25 grupos fraternos, en la que se entrevistaron a todos ellos. El objetivo del artículo es discutir: a) la articulación entre la conceptualización del objeto y las elecciones epistemológicas y metodológicas; b) la relevancia metodológica de las opciones con respecto a la elección de los temas a ser entrevistados; c) las ventajas de combinar las dos técnicas de recolección de datos.

Palabras clave: Investigación cualitativa; metodología; técnicas cualitativas; relaciones familiares; hermanos; complejidad. 


\begin{tabular}{|l|l|l|}
\hline Revista & & $\begin{array}{l}\text { Revista Latina de Sociología (RELASO) } \\
\text { Vol. 9, núm.2 (2019), pp. 4-23 } \\
\text { ISSN-e 2253-6469 } \\
\text { Dot: https://doi.org/10.17979/relaso.2019.9.2.6825 } \\
\text { de Sociologia }\end{array}$ \\
\hline
\end{tabular}

\section{ABSTRACT}

The article is the result of a sociological study on sibling relationships. The paper begins with a series of reflections on the phenomenon of sibling relationships, before moving on to examine the methodological options for a study of this type and their heuristic potential to provide insights into other phenomena. The study highlights the complexity and multiplicity of sibling relationships, arguing that any analysis must take into account the diversity and temporality of the subjects' individual and family experiences. For this reason, a qualitative approach is preferred, to account simultaneously for practices and representations, the everyday and the extraordinary, and the senses and meanings attributed to their experience by the sibling subjects of the study. The article describes the research process, arguing that the combination of data collection techniques used to explore the phenomenon of sibling relationships (in-depth life-story and photo-elicitation) may be transferable to other phenomena. The study was carried out in Portugal in 2018-2019 and involved a sample of 25 groups of siblings and half-siblings, all of whom were interviewed. The objective of the article is to discuss: a) consistency between the conceptual framework and the epistemological and methodological choices; b) the methodological relevance of the choice of interview topics; and c) the advantages of combining the two data collection techniques. Keywords: Qualitative research; methodology; qualitative techniques; family relationships; siblings; complexity. 


\begin{tabular}{|l|l|l|}
\hline Revista & Revista Latina de Sociología (RELASO) \\
Latina & Vol. 9, núm.2 (2019), pp. 4-23 \\
ISSN-e 2253-6469 \\
DOI: https://doi.org/10.17979/relaso.2019.9.2.6825
\end{tabular}

\section{Introdução}

Este artigo resulta de um conjunto de reflexões construídas com base numa investigação sociológica acerca das relações entre irmãs/os (Barbas, 2019). O texto apresenta algumas das opções metodológicas tomadas no decorrer da pesquisa, a partir de um posicionamento epistemológico específico, que encara este objeto na sua complexidade e multiplicidade (Law, 2004). Parafraseando Law (2004), quando este afirma que "existem diferentes objetos no mesmo objeto", a investigação em curso adota a ideia de que as relações entre irmãs/os são construídas por múltiplos atores, situações, tempos e espaços. Tomando como referência a posição epistémica de Law acerca da fluidez, turbulência, incoerência e imprevisibilidade da realidade, mas não assumindo os seus postulados "radicais" acerca do "método", pretende-se mostrar que, no interior de uma abordagem metodológica qualitativa "clássica" existe potencial para dar conta da "fractalidade" deste objeto1. Apresentam-se, assim os percursos seguidos no decorrer da pesquisa, defendendo-se que a combinação de técnicas "tradicionais" de recolha de dados - no caso entrevistas em profundidade e fotoelicitação - contém possibilidades heurísticas para a compreensão do fenómeno em análise, que podem ser transferíveis para distintos objetos.

A investigação que dá origem a esta reflexão foi realizada em Portugal, entre 2018 e 2019, e teve por base uma amostra composta por irmãs/os e meias/os irmãs/os, integradas/os em 25 fratrias. Os critérios de seleção foram construídos a partir da idade das mães (nascidas entre 1950-1969) e com base na heterogeneidade: por tipo de família (famílias nucleares e recompostas); por número de irmãs/os (2, 3, 4 ou mais elementos); por composição sexual das fratrias (femininas, mistas e masculinas); por região (rural ou urbana); e por escolaridade. O artigo estrutura-se em três pontos: no primeiro, apresenta-se a conceção do objeto de estudo e os desafios metodológicos por ela levantados; no segundo, destaca-se a importância das opções relativas à escolha dos sujeitos da investigação; finalmente, no terceiro ponto, apresentam-se as virtualidades das duas técnicas utilizadas - entrevistas em profundidade, com caráter de história de vida e foto-elicitação durante o momento da entrevista - para abordar um fenómeno complexo e múltiplo.

\footnotetext{
${ }^{1}$ Law vai buscar a ideia à matemática fractal, na qual uma linha pode, simultaneamente, existir em mais de uma dimensão, mas em menos do que duas. Para Law um "objeto fractal” é aquele que é "mais do que um mas menos do que vários” (2004, p. 62) 


\section{Revista \\ Latina \\ de Sociologia}

Revista Latina de Sociología (RELASO)

Vol. 9, núm.2 (2019), pp. 4-23

ISSN-e 2253-6469

DOI: https://doi.org/10.17979/relaso.2019.9.2.6825

\section{As fratrias: objeto complexo e múltiplo}

Gabb \& Fink (2015) caraterizam as relações, no caso, conjugais, como pragmáticas, mas também emocionais, assinaladas por escolhas ou até pela falta delas, com períodos de encantamento ou da falta dele, mas reconhecem sobretudo um espectro de muitos outros sentimentos e experiências (2015, p. 971). As autoras defendem que as emoções estão emaranhadas nas relações sociais, que se figuram como "cenários emocionais", onde se cruzam e sobrepõem micro e macro redes de relações (Burkitt, 2014, p. 20; Gabb \& Fink, 2015, p. 972). Especificamente, procuram ver estas relações como (re)feitas diariamente, com diferentes dinâmicas e configurações. Olhar as relações segundo esta perspetiva quotidiana permite abrir uma fenda analítica que "facilita uma análise multidimensional: material-temporal-emocional” (Gabb \& Fink, 2015, p. 972). O reconhecimento das relações familiares - sejam elas de que tipo - como quotidianamente (re)construídas é transversal a diversas/os autores/as (Finch, 2007; Gabb \& Fink, 2015; Harman \& Cappellini, 2015). Foi com base nessa perspetiva que se desenvolveu a investigação que dá origem a este artigo.

Morgan (1996) defende que as famílias contemporâneas são essencialmente definidas pelo "doing” - fazendo - mais do que pelo "being” - sendo. A autora afasta-se da família como estrutura e foca-se nas práticas familiares, observando-as como fragmentos da vida quotidiana, que fazem parte de sistemas mais amplos de significados (1996, p.190). Finch (2007) dialoga com Morgan (1996) mas vai mais além na sua proposta. Sugere que as relações familiares se reconhecem e desenvolvem a partir do "doing”, mas, sobretudo, do “displaying” (exibindo, demonstrando) (2007, p. 65). Ao introduzir este conceito, a autora pretende enfatizar a natureza social das práticas familiares e mostrar como estas se caraterizam por um processo em que os indivíduos ou grupos atuam na expetativa do entendimento, entre si, e pelos outros, do que é o "familiar" (2007, p. 67). Segundo esta perspetiva, a ação deve ser entendida pelo seu significado. Isto quer dizer que, não é suficiente realizar determinada ação nomeando-a “como de família”, mas será necessário que as pessoas envolvidas, bem como outras igualmente relevantes, a entendam, também, "como de família”. Metaforicamente, é como se os sujeitos estivessem em "palco a representar a sua relação de família”, e todos os intervenientes que participam nessa representação, tal como quem "assiste”, (re)conheçam essa ação como exclusiva do contexto familiar, não sendo replicável a outro.

Assim, entendem-se as relações entre irmãs/os como relações múltiplas, que integram uma parte da vida social dos sujeitos e que se constituem através de práticas quotidianas e familiares. As realizações dessas práticas familiares têm de ser entendidas como tal, por parte de quem as recebe, ou as vê. Isto, significa que não só a intenção inerente a essa prática, a essa ação, tem de ser entendida como "de irmã/o", mas quem recebe a ação, ou a vê, deve também a considerá-la de “irmã/o". 


\section{Revista \\ Latina \\ de Sociologia}

Revista Latina de Sociología (RELASO)

Vol. 9, núm.2 (2019), pp. 4-23

ISSN-e 2253-6469

DOI: https://doi.org/10.17979/relaso.2019.9.2.6825

Nas palavras dos sujeitos, as “coisas de irmãs/os” são aquelas que são partilhadas entre si: histórias, memórias, segredos. Algumas das autoras que trabalham com as relações familiares utilizam o conceito "sticky” para caraterizar estas relações (Smart, 2007; Davies, 2018). A proximidade, a intimidade e o "entrelaçamento" que caraterizam as relações de determinadas fratrias, ancoram-se no espaço e no tempo da coabitação prolongada, da partilha do espaço da intimidade, nas vivências de momentos diversos - momentos ordinários e quotidianos, mas, também, momentos extraordinários e irrepetíveis, episódios marcantes e significativos. Muitas vezes, estes últimos (re)configuram as relações entre os sujeitos e, por isso, devemos considerá-los.

Assim, compreenderam-se as relações fraternais numa perspetiva de trajetória de vida - questionando desde as primeiras memórias até à atualidade. Para tal, foi importante o contributo de Smart sobre o papel da linhagem e das memórias (2007; 2011). A autora discute como os ecos do passado estão entrelaçados no presente e criam significado um ao outro (2011, p. 543). Por isso, não podemos ignorar um passado que molda um presente.

Assumindo esta complexidade e multiplicidade, a proposta metodológica da pesquisa procurou integrar as diversas temporalidades, espacialidades e materialidades das relações fraternais, olhando para: as trajetórias individuais, as práticas familiares quotidianas e os eventos extraordinários, a diferenciação das relações entre irmãs/os face a outras (de parentesco e de amizade, por exemplo). Duas opções tomadas no trabalho de campo ancoram a proposta: entrevistar a totalidade da fratria e combinar duas técnicas de recolha de informação. De seguida defendem-se as suas virtualidades face aos desafios apresentados.

Todos e cada um/a: as vantagens de estudar a totalidade das fratrias

Smart \& Neale (1999) referem como a família é permeável a mudanças ao longo do tempo, refletindo-se nas práticas, nas identidades e nas relações (Smart \& Neale, 1999, p. 85). Entrada de novos membros, saída de outros, casamentos e divórcios, nascimentos e mortes, mobilidade geográfica, processos de reconstituição familiar são exemplos de como este objeto se (re)configura continuamente. Assim sendo, quem entrevistar para compreender as relações entre irmã/os?

McCarthy et al. (2003) mostram como conversar com todos os elementos da família confere à/ao investigador/a uma visão panorâmica (2003, p. 15). A construção do conhecimento faz-se através de um caleidoscópio analítico, que sempre que é remexido conduz a outras questões, a outras perspetivas (idem, p. 19).

Mason (2011) propõe a "abordagem de facetas”, que se preocupa mais com a forma de recolha dos dados, do que propriamente com a maximização dos mesmos, de forma descritiva (2011, p. 75). A autora recorre à metáfora visual de uma pedra preciosa - a sua proposta é criar um conjunto de facetas que respondam às linhas de investigação, sendo que o rigor da abordagem resulta no modo como a/o investigador/a encontra para captar as múltiplas facetas de um fenómeno, através de diferentes perspetivas (Mason, 2011, p. 77). Sobre isto, Gabb \& Fink (2015) afirmam que não existe uma única pedra preciosa de um fenómeno (2015, p. 977). As relações (conjugais, no caso do seu trabalho) são complexas e difíceis de compreender devido às variáveis que se sobrepõem: o individual; o coletivo; a unidade social; os contextos biográficos; entre outros (Gabb \& Fink, 2015, p. 977). 


\begin{tabular}{|l|l|l|}
\hline Revista & $\begin{array}{l}\text { Revista Latina de Sociologia (RELASO) } \\
\text { Vol. 9, núm.2 (2019), pp. 4-23 } \\
\text { ISSN-e 2253-6469 } \\
\text { DoI: https://doi.org/10.17979/relaso.2019.9.2.6825 }\end{array}$ \\
\hline
\end{tabular}

Partindo destas concepções metodológicas, a resposta para a pergunta quem entrevistar na pesquisa, foi a totalidade da fratria2. Não se trata de obter perspetivas contrastantes, em que uma ou outra seja mais ou menos verdadeira, mas sim, como se detalha de seguida, de construir um caleidoscópio que capta as diferentes "texturas” (Law, 2004, p. 6) do objeto. Entrevistar todas/os as/os irmãs/os permite cruzar "nós” e "eu”, singular e múltiplo, estrutura e dinâmica, "being”, "doing” e "displaying”.

Entrevistar toda a fratria faz com que os sujeitos assumam que a/o investigador/a dispõe de informação prévia à sua própria entrevista, o que conduziu por diversas vezes à "descoberta” de novos elementos. A assunção do conhecimento e o efetivo desconhecimento do que já foi revelado ou não pelos outros, trouxe novas histórias, novas informações e novos dados para a investigação. Veja-se o seguinte exemplo. A irmã mais nova não referiu que tinha existido um terceiro irmão. Entrevistar o irmão mais velho trouxe esse novo dado à investigação. No discurso de Artur:

“ Não sei se a Eva falou [na entrevista com a irmã], mas nós tivemos um irmão que faleceu antes de eu nascer. Portanto, tivemos um outro irmão mais velho. (Artur Lemos, fratria nuclear, díade, mista) 3

\footnotetext{
${ }^{2}$ A opção de entrevistar a totalidade das fratrias implicou considerar apenas famílias em que todos os elementos da fratria estivessem de acordo em ser entrevistadas/os. Esta opção teve implicações na morosidade do trabalho de campo.

${ }^{3}$ Por se reconhecer, que a tipologia do núcleo familiar de origem (nuclear ou recomposto) e as caraterísticas da fratria são relevantes para as diferentes perspetivas, para efeitos de caraterização nos excertos transcritos são enunciadas as seguintes caraterísticas: tipologia familiar (nucleares ou recompostas); dimensão - díade (2 elementos), tríade (3 elementos) ou alargada (4 elementos ou mais) e por composição sexual - mista, feminina ou masculina.
} 


\begin{tabular}{|l|l|l|}
\hline Revista & $\begin{array}{l}\text { Revista Latina de Sociologia (RELASO) } \\
\text { Vol. 9, núm.2 (2019), pp. 4-23 } \\
\text { ISSN-e 2253-6469 } \\
\text { DOt: https://doi.org/10.17979/relaso.2019.9.2.6825 }\end{array}$ \\
\hline
\end{tabular}

\subsection{As “nossa(s) história(s)"}

Entrevistando a totalidade das fratrias é possível identificar elementos comuns a todas as narrativas. Há episódios, situações e histórias que todos/as referem. Objetivo e subjetivo convergem para uma mesma descrição de um “domínio que é de todos”. Cada família dispõe de um certo número de atributos e de referências identitárias que funcionam como símbolos de reconhecimento e diferenciação social a partir dos quais se situa a identidade singular do indivíduo (Portugal, 2014). O conjunto destes elementos fornece uma espécie de carta comum a todos os membros do grupo familiar cujo código é transmitido, negociado, apropriado e reapropriado, construindo ao longo do tempo a identidade familiar e definindo, a partir de uma mesma trama coletiva, a identidade pessoal de cada um (Bertaux-Wiame; Muxel, 1996; Pina Cabral, 2003).

A mesma informação repetida por todas/os dá conta desta construção - do que é comum, vulgar, consensual, o que não é segredo e o que é partilhado por toda a fratria. Destacam-se sobretudo questões ligadas aos quotidianos, às práticas e aos rituais familiares. Veja-se o caso da celebração do Natal, descrita por dois irmãos:

“A mãe do meu pai que vivia [local] era a pessoa mais impulsionadora do Natal. De levar tudo a toda a gente (...) procurava juntar a família toda, porque vinha de uma família que tinha muitos irmãos. Quer dizer, isto é, uma amalgama de gente. Completamente. E, nós, na altura, fazíamos os Natais ali na casa do [local]. Porque era uma casa que permitia... era a casa maior que entre todos tínhamos e que no Natal era extremamente pequena para tanta gente. Aliás, há fotografias em álbuns perdidos algures, mas lembro-me de ver fotografias em que havia, aí bem há vontade 40, 50 pessoas no jantar e no almoço de Natal.” (Gustavo Antunes, fratria nuclear, díade, mista).

"Enquanto a minha avó paterna foi viva, e teve a casa no [local] foram sempre uns Natais muito grandes. Vinha a família de [local], vinha do lado da minha mãe, juntávamo-nos todos, muito vivos, muito convívio! Tudo decorado, muita criançada, tudo a mexer de brincadeiras.” (Maria Antunes, fratria nuclear, díade, mista).

\subsection{As diferentes versões das "nossa(s) história(s)"}

Existindo elementos que são do conhecimento de todas/os, as perspetivas e narrativas são individuais e subjetivas. Isto é, um tema/episódio/situação pode ser identificada por todos os elementos da fratria, mas apresentar diferentes interpretações para cada pessoa. Entrevistar toda a fratria permite compreender os significados singulares da(s) história(s), que são construídas num “nós” familiar, mas individualmente interpretadas. Girando o caleidoscópio, geram-se novas imagens.

Veja-se o exemplo de Caetana e Filipe. Ambos identificaram nas suas entrevistas um período de afastamento. Os motivos para cada um são, no entanto, diferentes: 


\begin{tabular}{|l|l|l|}
\hline Revista & $\begin{array}{l}\text { Revista Latina de Sociología (RELASO) } \\
\text { Vol. 9, núm.2 (2019), pp. 4-23 } \\
\text { ISSN-e 2253-6469 } \\
\text { DOI: https://doi.org/10.17979/relaso.2019.9.2.6825 }\end{array}$ \\
\hline
\end{tabular}

“Ele não tem uma boa relação com o meu pai. E o tema do meu pai só há coisa de... para aí há uns 3 anos... é que a gente falámos, assim mais a sério (...) tive mesmo que chegar ao pé dele - porque sei que é um tema que o magoa - e dizer-lhe: a gente tem de falar sobre isto. Porque pode acontecer uma situação mais chata e eu quero saber a tua opinião (...) aí é que a gente esteve assim (...), se calhar, prejudicou um bocadinho a nossa relação, não que nós façamos para afetar. Porque nós falámos sobre as coisas. A ideia que nós tínhamos do assunto, eu tinha uma ideia, e ele tinha outra... se calhar, chocou-nos um bocado. Tanto de um lado, como do outro. (Caetana José, fratria recomposta, díade, mista)

“A gente é assim... a gente houve uma altura que a gente todas as semanas íamos comer à casa dela ou ela ia comer à nossa casa. Depois o que é que aconteceu? A gente cortamos um bocadinho, mas acho que foi mais... não sei bem explicar (risos). O marido dela é muito bom moço. É um moço excelente, é... só que tem um pequeno defeito: é muito sabichão. E pá e as pessoas sabichonas que sabem tudo, que sabem sempre tudo, chega a um ponto que uma pessoa começa a saturar. E a prova é que eles se começaram a cortar muito com muitos amigos que a gente tem de longa data. Porque eles próprios veem a atitude do rapaz. E todos dizem: ele é bom rapaz! O problema é aquele feitio que ele tem que quer ser sempre melhor, ou tudo o que ele faz é melhor, do que todos os outros. E pá e as pessoas quando são assim começa a ser um bocado chato. E acho que a minha irmã na altura começou a perceber isso. $\mathrm{E}$ para não arranjar ou mal-estar, ou conflitos, começou-se a afastar um bocado (...) mas o que é certo é que eu notei esse pequeno afastamento que ela teve.” (Filipe José, fratria recomposta, díade, mista)

\subsection{A história de cada um/a}

Aceder às perspetivas individuais permite identificar elementos que são significativos apenas para um elemento da fratria. As razões para as variações a partir da história comum são múltiplas. Por um lado, o ciclo de vida familiar produz, necessariamente, trajetórias individuais diferentes. Assim, há situações descritas por determinados elementos que não fazem sentido para outros, porque não as experienciaram. Por outro lado, há um mundo de “não-ditos”, que faz com que algumas histórias não sejam partilhadas por toda/os.

No caso, traz-se o discurso de uma irmã mais velha, fruto da primeira relação conjugal da mãe: 


\begin{tabular}{|l|l|l|}
\hline Revista & $\begin{array}{l}\text { Revista Latina de Sociologia (RELASO) } \\
\text { Vol. 9, núm.2 (2019), pp. 4-23 } \\
\text { ISSN-e 2253-6469 } \\
\text { DoI: https://doi.org/10.17979/relaso.2019.9.2.6825 }\end{array}$ \\
\hline
\end{tabular}

“(...) o meu padrasto. Espetacular no início, fantástico. O melhor pai de sempre. Depois tornou-se aquela coisa diabólica. Expulsou-nos de casa uma vez. A mim e à minha irmã [do meio]. E pronto. E depois... quando saímos de casa acho que foi quando tudo melhorou. Quando a Rute foi para a Universidade. Eu também. Acho que eles sentiram que o peso saiu. E depois começaram-se a tornar mais equilibrados [a mãe e o padrasto]. Mas nós tínhamos que estar longe. E temos que estar longe. Porque quando estamos muito tempo as coisas degradam-se. (...) Acho que eles criaram aquela família [eles os dois juntamente com a irmã mais nova] e encontraram o equilíbrio ali. E podemos ir ao fim de semana e estar lá uma semana de férias, mas não muito mais do que isso. Acho que é... Não sei. É aquele equilíbrio de família entre eles. Encontraram ali o equilíbrio. Estão equilibrados, está tudo bem. Por isso... venho uma semana, duas no máximo de férias. E o meu maior medo de ficar desempregada era ter de voltar para casa.

E. E qual é a perceção que vocês têm que a Ana tem? Da vossa família... e. Que é equilibrada. Que está tudo bem. Eu acho que para... a Ana não tem perceção nenhuma disto. Ela foi muito protegida, sempre. E ainda bem! O meu padrasto sempre a protegeu muito. (...) Então a perceção que eu acho que ela tem de família é uma família tranquila, normal, tradicional. Nem sequer se apercebe...

E. Vocês nunca partilharam estas coisas?

Não. (...) mas acho que nunca falamos com ela sobre isto porque são coisas muito dolorosas. Que eu acho que não queremos estar a levantar poeiras. Então preferimos ignorar o assunto. (...) quando estamos com ela nunca falamos sobre isto, nem demonstramos que há ali duas famílias.” (Benedita Cartaxo, fratria recomposta, tríade, feminina)

Na voz da irmã Ana:

"Eu penso que seja mais próxima do meu pai porque nós temos uma personalidade muito similar. A minha mãe sempre foi uma pessoa muito difícil, mas fazia qualquer coisa para me proteger. Eu sempre... eu acho isso muito importante. Apesar das nossas personalidades não coincidirem muito bem, eu penso que... nós faríamos qualquer coisa para nos protegermos uma à outra." (Ana Cartaxo, fratria recomposta, tríade, feminina)

\section{5 “Quem é quem?” na fratria e na família}

O lugar que cada pessoa ocupa na família e a sua posição na fratria é um elemento importante para a compreensão das relações entre irmã/os (Barroso, 2011; Barbas, 2014). A perspetiva de cada membro sobre a família, as relações familiares e fraternais é situada. Resulta da sua condição, do seu lugar, do seu papel, das suas vivências e experiências. Entrevistar cada elemento, individualmente, foi fundamental para dar conta desta perspetiva. 


\begin{tabular}{|l|l|l|}
\hline Revista & $\begin{array}{l}\text { Revista Latina de Sociología (RELASO) } \\
\text { Vol. 9, núm.2 (2019), pp. 4-23 } \\
\text { ISSN-e 2253-6469 } \\
\text { Dol: https://doi.org/10.17979/relaso.2019.9.2.6825 }\end{array}$ \\
\hline
\end{tabular}

Aceder aos diferentes discursos permite situar os elementos no grupo. O conhecimento acerca das representações de si e dos outros permite identificar formas de organização familiar e o lugar de cada um, assim como, dinâmicas relacionais específicas. Nas palavras de Helena:

“Os meus irmãos sempre tiveram uma relação mais próxima, eles, os dois. Apesar de nos darmos sempre todos muito bem, mas o meu irmão e a minha irmã têm uma relação mais próxima a nível de confidências e de assuntos mais pessoais. Porque... pronto cada um tem a sua vida, não é? Apesar de nos darmos bem há assuntos que dizem respeito a cada um. (...) mas sempre foram assim mais confidentes, os dois.” (Helena Cerveira, fratria nuclear, tríade, mista)

Nas palavras do seu irmão Abel:

"Eu sempre tive ao longo da vida uma relação mais próxima com a minha irmã mais nova do que com a minha irmã mais velha (...) uma parte será seguramente por aquilo que eu já disse. O facto da minha irmã mais velha ser... estar muito mais próxima daquilo que os meus pais queriam. E, portanto, eu sempre a vi como fazendo parte do sistema e eu a querer combater o sistema. E, ao mesmo tempo, sentir que combater o sistema era também abrir algum caminho para a minha irmã mais nova." (Abel Cerveira, fratria nuclear, tríade, mista)

\subsection{Uma e outra(s) família(s)}

Olhar os dados de forma panorâmica e caleidoscópica mostrou que a partir da identificação de uma primeira família, é possível chegar a outras famílias. Isto revelou-se particularmente relevante nas famílias recompostas. Falar com o irmão que resultou de uma primeira união, não é o mesmo que falar com a irmã da segunda união. Tiveram e viveram diferentes famílias, e as suas perceções partem de diferentes experiências e vivências. São histórias diferentes, protagonistas diferentes, ciclos de vida familiares diferentes, práticas diferentes. E nesta trama constroem-se sujeitos e relações distintas e desiguais.

Veja-se o discurso de Caetana sobre o "tema tabu":

"Se bem que o tema pai, o tema mãe, e a relação de uns para os outros é assunto que acaba por não existir [entre irmãos]. Para nós conseguirmos darmo-nos bem sem divergências de opinião nesses campos, porque é complicado. E para o Filipe é muito complicado falar sobre isso. E eu também não quero entrar nesse espaço, porque isso é a história dele, não é a minha. Porque eu chegueilhe a dizer: "o teu pai para ti foi uma pessoa, para mim é outra”. E então a gente não pode e aí não temos termo de comparação. Embora, eu acho que... E compreendo e sei a história dele”. (Caetana José, fratria recomposta, díade, mista)

E a desigualdade revelada nas palavras de Moisés: 


\begin{tabular}{|l|l|l|}
\hline Revista & $\begin{array}{l}\text { Revista Latina de Sociologia (RELASO) } \\
\text { Vol. 9, núm.2 (2019), pp. 4-23 } \\
\text { ISSN-e 2253-6469 } \\
\text { Dor: https://doi.org/10.17979/relaso.2019.9.2.6825 }\end{array}$ \\
\hline
\end{tabular}

"O meu pai dizia: o tacho está na mesa, come tudo do tacho, e não se faz comidas diferentes para cada pessoa. E a minha irmã, o meu irmão sentavamse à mesa e comiam o que estava no tacho. Fosse caldeirada, fosse bifes, fosse ovos estrelados. E a minha irmã sentava-se e dizia: epá, não gosto. E a minha avó vinha: Ah! Então quer um ovinho estrelado minha menina? E ia-lhe fazer um ovo estrelado. E eu ficava assim a olhar para aquilo, vendo a diferença. Sempre... isto fez-me um pouco de confusão. Porque eu via perfeitamente a diferença entre o tratamento dos meus irmãos da parte do meu pai, e o tratamento da minha irmã. E via isto tudo a acontecer à frente dos meus olhos e não podia dizer nada porque não tinha autoridade para o fazer.” (Moisés Cerqueira, fratria recomposta, alargada, mista).

Segundo o discurso de Adelaide:

"Porque as minhas irmãs já tiveram uma juventude totalmente diferente. A da Clara já foi um bocadinho diferente da minha e da Amélia. E a Ema então! Pronto, foi totalmente... Eu nunca fiz férias com o meu marido [quando eram namorados], eu nunca fiz nada. A Ema não. A Ema fazia, pronto. A Ema foi a juventude dela já... como é agora [risos]. Muito, muito diferente.” (Adelaide Amorim, fratria nuclear alargada feminina)

O entendimento de Benedita:

“A minha mãe começou a tirar férias com o meu padrasto. Ou seja, acabou por haver ali uma distinção. Tanto que, por exemplo, agora... mesmo agora [nos dias de hoje] mas já não me aflige. Nem a mim, nem à minha irmã [a do meio]. Quando vão jantar [fora] é os 3 [padrasto, mãe e irmã mais nova], quando nós não estamos em casa. Porque se estivermos em casa comemos em casa (...) mas acontece sempre. Quando vão fazer um passeio, uma viagem ou comer fora é a 3, nunca é a 4, ou a 5. Mas tentamos nem sequer pensar nisso.” (Benedita Cartaxo, fratria recomposta, tríade, feminina)

\section{II.- As vantagens de combinar técnicas}

O olhar caleidoscópico que permitiu dar conta das imagens acima parcialmente desvendadas ancorou-se em duas técnicas qualitativas - as entrevistas em profundidade e a foto-elicitação. Como inicialmente se afirmou, pretende-se, neste texto, defender um posicionamento metodológico que destaca as virtualidades destas duas técnicas e, sobretudo, da sua combinação, para dar conta das diferentes camadas e texturas de informação contidas no objeto estudado. O uso das entrevistas e da foto-elicitação foi fundamental para desenvolver (re)construções analíticas e responder ao "quem", “quando" e "porquê" das relações entre irmã/os. 


\begin{tabular}{|c|c|}
\hline $\begin{array}{l}\text { Revista } \\
\text { Latina } \\
\text { de Sociologia }\end{array}$ & $\begin{array}{l}\text { Revista Latina de Sociología (RELASO) } \\
\text { Vol. 9, núm.2 (2019), pp. 4-23 } \\
\text { ISSN-e 2253-6469 } \\
\text { DOI: https://doi.org/10.17979/relaso.2019.9.2.6825 }\end{array}$ \\
\hline
\end{tabular}

\subsection{As entrevistas}

Recuperando a ideia do "empirismo irredutível" das entrevistas apontado por Kaufmann (1996, p. 16), ao citar Schwartz, considerou-se que esta técnica apresentaria diversas vantagens para o entendimento das relações fraternais, dando conta da sua complexidade. Optou-se por entrevistas em profundidade com "caráter de história de vida". Não se trata de usar as histórias de vida como uma alternativa radical ao modo de fazer pesquisa, na senda de Bertaux (1980) ou de Ferrarotti (1983), mas sim de reconhecer alguns dos contributos desta abordagem para a pesquisa na área da família (Portugal, 2006, p. 161). Numa entrevista em que se apela à construção de uma "história de vida" vemos que o indivíduo não se limita a "desfiar" uma série de acontecimentos, esforça-se por conferir sentido ao passado e, ao mesmo tempo, à situação presente, vendo, também, o que ela contém de projetos de futuro. Ao organizar a sua biografia, o indivíduo confere sentido e totalidade a uma vida fragmentada e dividida por circunstâncias e acontecimentos diversos (Portugal, 2006, p. 162).

A narrativa biográfica permitiu um olhar longitudinal, que obteve uma descrição detalhada das trajetórias, situando os momentos mais marcantes das relações e compreendendo os sentimentos, pontos de vista e perspetivas dos membros das fratrias (Atkinson, 2002). Possibilitou, assim, a apreensão de um conjunto de variáveis e processos que dão conta de um fator aparentemente paradoxal: "a diacronia do sincrónico" (Ferrarotti, 1983, p. 29).

De um ponto de vista operacional, foi possível obter: uma descrição detalhada das trajetórias pessoais e familiares; as narrativas acerca das relações fraternais; a identificação das temporalidades das relações; as descrições da quotidianidade e das rotinas, assim como dos momentos marcantes e extraordinários. Através da recolha de todos estes elementos para a totalidade da fratria, como acima exposto, as entrevistas permitiram compreender as diferentes perspetivas do grupo de irmãs/os e as formas de construção de subjetividade no interior do "nós" familiar.

Veja-se, a "história da relação” de Rute e Benedita: 


\begin{tabular}{|l|l|l|}
\hline Revista & $\begin{array}{l}\text { Revista Latina de Sociología (RELASO) } \\
\text { Vol. 9, núm.2 (2019), pp. 4-23 } \\
\text { ISSN-e 2253-6469 } \\
\text { DOI: https://doi.org/10.17979/relaso.2019.9.2.6825 }\end{array}$ \\
\hline
\end{tabular}

"Recordo-me que a minha relação com a Benedita não foi muito fácil [na infância]. Nós discutíamos muito quando éramos pequenas. Não sei se era normal, mas nós tínhamos uma relação muito turbulenta. E acho que foi isso que marcou mais a minha infância. Mas ao mesmo tempo éramos muito más uma para a outra. Éramos muito competitivas e gostávamos muito de chamar a atenção dos nossos pais. [depois de descrever o divórcio da mãe com o pai acrescenta] eu e a Benedita fomos das primeiras a ter pais divorciados na escola. Foi um grande choque para muita gente, ainda não era muito normal. Então muita gente fazia perguntas na escola (...) e eu e a Benedita acabamos por nos aproximar mais no ano em que estivemos sozinhas com a minha mãe, porque a minha mãe também não estava muito bem nesse ano. Foi um ano de recomposição e de aceitar que acabou. Então eu e a Benedita tivemos que nos unir mais. [mais à frente acrescenta] nós mudámos a nossa relação a certa altura quando ela começou a olhar para mim mais como pessoa, e não como animal de estimação. E começou a encarar-me como uma rapariga, como uma amiga. E foi na nossa adolescência que começámos a ficar com uma relação mais forte. E foi até através de asneiras, de encobrir asneiras uma da outra, e depois começaram os rapazes, se calhar os primeiros cigarros, as primeiras bebedeiras. Em que nós nos encobrimos muito uma à outra e percebemos que tínhamos uma personalidade muito parecida. E depois começamos a partilhar amigos, a partilhar histórias. E começámos a ser melhores amigas. (...) e certa altura, por volta dos meus 16, 17 anos nós construímos a nossa amizade, e acho que a partir dos 18 anos, quando eu fui para a Universidade deixou de haver uma linha que separava a irmã mais nova da irmã mais velha, começou só a ser uma amizade.” (Rute Cartaxo, fratria recomposta, tríade, feminina)

\subsection{A foto-elicitação?}

O recurso à técnica da foto-elicitação partiu da dificuldade de investigadores de diferentes áreas científicas chegarem a consensos sobre categorias analíticas. Collier (1957) utilizou a técnica face a um problema específico encontrado enquanto trabalhava numa equipa multidisciplinar. Foram realizadas entrevistas às mesmas pessoas com o recurso à fotografia, e sem este recurso, sendo revelados diversos benefícios na utilização da técnica: maior fluidez da situação de entrevista; estimulação da memória dos sujeitos e minimização dos momentos de incompreensão.

Harper (2002) entende que introduzir uma fotografia na investigação permite chegar a outro tipo de conhecimento, pois conduz a novas informações, memórias e sentimentos (p. 13). Existem diversas formas de integrar as fotografias nas investigações: levar fotografias para que as/os entrevistadas/os falem sobre elas; solicitar aos sujeitos que levem uma fotografia consigo no momento da entrevista ou pedir que tirem fotografias para falar sobre elas, dando-lhes voz sobre os momentos que captaram (Harper, 2002; Radley, 2010). 


\begin{tabular}{|l|l|l|}
\hline Revista & & $\begin{array}{l}\text { Revista Latina de Sociologia (RELASO) } \\
\text { Vol. 9, núm.2 (2019), pp. 4-23 } \\
\text { ISSN-e 2253-6469 } \\
\text { Latina }\end{array}$ \\
de Sociologttps://doi.org/10.17979/relaso.2019.9.2.6825 \\
\hline
\end{tabular}

Na investigação que aqui se relata, pediu-se que as pessoas levassem para a entrevista uma fotografia representativa "da sua história de irmãs/os". Como realizado em outras investigações (Radley 2010, p. 268), convidou-se as/os entrevistadas/os a refletirem sobre as suas relações, com base numa imagem particular, escolhida pelos próprios.

A partir das fotografias escolhidas foi possível obter novas "texturas" sobre os temas abordados nas entrevistas. Algumas pessoas revelaram momentos comuns, como almoços e jantares de família, fotografias com os animais de estimação; outras escolheram eventos extraordinários, outras, ainda, mostraram momentos que identificaram como marcantes na sua história de vida. Assim, por um lado, o uso das fotos permitiu, simultaneamente, olhar o quotidiano e o extraordinário, através da descrição mais densa de momentos e acontecimentos e, por outro, obter narrativas diferenciadas sobre o "ser irmã/o", sendo um elemento fundamental para conhecer o "display” das relações.

Vejam-se os seguintes exemplos:

"Podiam ter sido várias [fotografias] mas esta... esta... como foi um acontecimento que eu vivi este ano, e que foi dos acontecimentos mais importantes da minha vida - que foi o meu casamento - acho que representa bem aquilo que também é o meu irmão. Que é uma pessoa bastante importante naquilo que eu sou hoje e pronto. Isto foi de manhã antes de sair para a igreja, e pronto. Ele [o irmão] estava mais nervoso que eu." (Pedro Mateus, fratria nuclear, díade, masculina). 


\begin{tabular}{|l|l|l|}
\hline Revista & $\begin{array}{l}\text { Revista Latina de Sociologia (RELASO) } \\
\text { Vol. 9, núm.2 (2019), pp. 4-23 } \\
\text { ISSN-e 2253-6469 } \\
\text { Dot: https://doi.org/10.17979/relaso.2019.9.2.6825 }\end{array}$ \\
\hline
\end{tabular}

"Esta fotografia foi tirada... foi uma selfie que tiramos em Nova Iorque, num teatro. E eu escolhia, podia ter escolhido qualquer outra, mas escolhia porque foi o realizar de um sonho das duas [irmãs]. Tínhamos pensado já... tínhamos esse sonho em comum de ir a Nova Iorque e termos o interesse comum em teatro musical e... e então quando fomos. Aliás, tínhamos planeado anos antes o que íamos fazer. E ir à Broadway era um dos objetivos. Era o maior até, para mim. E pronto tirámos esta selfie mesmo antes de começar o espetáculo. E pronto, faz-me lembrar isso. Um objetivo em comum, e que fomos juntas, lá. Podia ter sido qualquer outra dessa viagem, ou até quando eramos mais pequenas, mas a do teatro tem ainda mais sentido porque é uma coisa que estamos sempre a falar. Quando sai uma peça nova, quando ela vai ter comigo a [local] vamos sempre ao teatro. É uma coisa que nos une. E que temos um interesse partilhado. (Sofia Leite, fratria nuclear, díade, feminina) "Portanto, isto somos nós [irmãos] naturalmente. Eu, a minha irmã mais velha, a Helena e a Diana. E eu escolhi esta fotografia porque na minha memória... eu não sei... eu lembro-me do dia. Lembro-me de estar... isto é na aldeia da minha mãe. (...) e eu lembro-me de estar, era um dia de festa e... Isto aqui atrás, por detrás é uma igreja. Então nós estávamos... tínhamos ido... tínhamos ido à missa e havia uma procissão. E nós estávamos ali no adro da igreja os 3. E alguém nos viu e tirou uma fotografia e depois deu aos nossos pais. E na minha memória este foi o primeiro dia em que eu percebi... ou melhor, foi o dia em que eu percebi que era irmão mais novo, mas também era irmão mais velho. E foi por isso que eu escolhi esta fotografia.” (Abel Cerveira, fratria nuclear, tríade, mista)

\section{Conclusões}

Este texto procura dar um contributo para a investigação qualitativa, discutindo as vantagens da combinação de diferentes técnicas de recolha de dados e da inclusão das perspetivas de diferentes sujeitos. Partindo-se na investigação de base, da conceção das relações entre irmãs/os enquanto objeto complexo e múltiplo, explicita-se os caminhos metodológicos para construir um olhar caleidoscópio e uma visão panorâmica que trouxe várias camadas de dados e diferentes “texturas” (Law, 2004).

Através das diferentes posições, das diversas narrativas e interpretações, é possível compreender o lugar de cada elemento na fratria e na família e as temporalidades das relações. Percebe-se, assim, que o fenómeno não é singular, tem diferentes matizes, e não existe apenas uma forma de ser irmã/o e de fazer e demonstrar as relações fraternais.

A combinação das duas técnicas de análise qualitativa permitiu chegar das interações mais invisíveis às mais visíveis, aos episódios quotidianos e ordinários, mas também aos momentos extraordinários e irrepetíveis. Por oposição a outras relações, entendeu-se o que é de irmãs/os, e o que não é. 


\begin{tabular}{|l|l|l|}
\hline Revista & Revista Latina de Sociología (RELASO) \\
Latina & Vol. 9, núm.2 (2019), pp. 4-23 \\
ISSN-e 2253-6469 \\
DOI: https://doi.org/10.17979/relaso.2019.9.2.6825
\end{tabular}

Procura-se, assim, uma abordagem metodológica que contribua, também, de modo mais amplo, para a reflexão sobre objetos dinâmicos e multidimensionais. Cabe à pesquisa qualitativa reconhecer a complexidade dos objetos de estudo, desenhando investigações que deem conta dos desafios epistemológicos e metodológicos levantados por esta conceção. Assim, a proposta aqui apresentada pretende mostrar como é possível aplicar técnicas de recolha de informação que minimizam o desconhecimento e possibilitam a construção de categorias analíticas fora das dicotomias tradicionais. De modo particular, no caso do objeto de estudo, por exemplo, sair da matriz dos irmãos "mais velhos" e "mais novos" ou das relações «harmoniosas» ou «conflituosas». Para tal, é necessário estar atento às informações inesperadas que os sujeitos trazem, permitidas pela combinação das técnicas de recolha de dados, de modo a produzirem novos olhares, novos entendimentos, novos conhecimentos. 


\begin{tabular}{|l|l|l|}
\hline Revista & $\begin{array}{l}\text { Revista Latina de Sociología (RELASO) } \\
\text { Vol. 9, núm.2 (2019), pp. 4-23 } \\
\text { ISSN-e 2253-6469 } \\
\text { Dol: https://doi.org/10.17979/relaso.2019.9.2.6825 }\end{array}$ \\
\hline
\end{tabular}

\section{Referências Bibliográficas}

Atkinson, R. (2001). The Life Story Interview. In Gubrium, J. \& Holstein, J. (Eds.), Handbook of Interview Research (pp 121-140). Thousand Oaks: Sage.

Barbas, A. (2014). Crescer a meias: uma análise sociológica do impacto dos estilos educativos parentais nas relações entre irmã/os. Dissertação de Mestrado, Coimbra, Faculdade de Economia da Universidade de Coimbra

Barbas, A. (2019). (Des)focos analíticos e investigação qualitativa: reflexões metodológicas sobre as fratrias como objeto dinâmico e multidimensional. In Atas - Investigação Qualitativa em Ciências Sociais/Investigación Cualitativa en Ciencias Sociales, 3, 297-306.

Barroso, M. (2011). Social perceptions of siblings' sexual composition: evidence from Portuguese youth. Journal of Comparative Family Studies,42 (5), 687-702. doi: 10.3138/jcfs.42.5.687

Bertaux, D. (1980). L’approche biographique: sa validité méthodologique, ses potentialités. Cahiers Internationaux de Sociologie. vol. LXIX

Bertaux-Wiame I. \& Muxel, A. (1996). "Transmission familiale:territoires imaginaires, échanges symboliques et inscription sociale." In François de Singly et al. (Eds.) La Famille en questions: État de la Recherche (pp 187-210). Paris: Éditions Syros.

Burkitt, I. (2014). Emotions and Social Relations. London: Sage.

Collier, J. Jr. (1957). Photography in anthropology: a report on two experiments. American Anthropologist, 59, 843-859. doi: 10.1525/aa.1957.59.5.02a00100

Davies, K. (2018). 'Sticky' proximities: Sibling relationships and education. The Sociological Review, 67 (1), 210-225. doi: 10.1177/0038026118784832

Ferrarotti, F. (1983). Histoire et histoires de vie - la méthode biographique en sciences sociales. Paris: Méridiens.

Finch J. (2007). Displaying families. Sociology, 41(1), 65-81. doi: $10.1177 / 0038038507072284$

Gabb J. \& Fink, J. (2015). Telling Moments and Everyday Experience: Multiple Methods Research on Couple Relationships and Personal Lives. Sociology, 49(5), 970-987. doi: 10.1177/0038038515578993

Harman, V. \& Cappellini, B. (2015). Mothers on Display: Lunchboxes, Social Class and Moral Accountability. Sociology, 49(4), 764-78. doi: 10.1177/0038038514559322

Harper, D. (2002). Talking about pictures: A case for photo elicitation. Visual Studies, 17(1), 13-26. doi:10.1080/14725860220137345

Kaufmann, J. (1996). L’entretien Compréhensif. Paris: Éditions Nathan.

Law, J. (2004). After Method: Mess in Social Science Research. London: Routledge.

Mason J. (2011). Facet methodology: The case for an inventive research orientation. Methodological Innovations Online, 6(3), 75-92. doi: 10.4256/mio.2011.008

McCarthy, J., Gillies V., \& Holland, J. (2003). Multiple perspectives on the 'family' lives of young people: methodological and theoretical issues in case study research. International Journal of Social Research Methodology, 6(1), 1-23. doi: 10.1080/13645570305052

Morgan, D. (1996). Family Connections. Cambridge: Polity Press. 


\begin{tabular}{|l|l|l|}
\hline Revista & & $\begin{array}{l}\text { Revista Latina de Sociología (RELASO) } \\
\text { Vol. 9, núm.2 (2019), pp. 4-23 } \\
\text { ISSN-e 2253-6469 } \\
\text { Iatina }\end{array}$ \\
de Sociol https://doi.org/10.17979/relaso.2019.9.2.6825 \\
\hline
\end{tabular}

Pina Cabral, J. (2003). O homem na família. Cinco ensaios de Antropologia. Lisboa, ICS/Imprensa de Ciências Sociais.

Portugal, S. (2006). Novas Famílias, Modos Antigos. As redes sociais na produção de bemestar. Tese de Doutoramento em Sociologia, Coimbra, Faculdade de Economia da Universidade de Coimbra.

Portugal, S. (2014). Família e Redes Sociais: Ligações Fortes na Produção de Bem-Estar. Coimbra: Almedina.

Radley, A. (2010). What people do with pictures. Visual Studies, 25(3), 269-279. doi: 10.1080/1472586X.2010.523279

Smart C. (2007). Personal Life. Cambridge: Polity Press.

Smart, C. (2011). Families, Secrets and Memories. Sociology, 45(4), 539-553. doi: $10.1177 / 0038038511406585$

Smart, C., Neale, B. (1999). Family Fragments?. Cambridge: Polity Press. 